\title{
A Dynamic Model for Simulating Recombinant Protein Production in Transgenic Lettuce for Optimum Environmental Control
}

\author{
Tsuyoshi OKayama, Takenori Kanai*, Mirwan UshadA*, Kenichi OKamura \\ and Haruhiko MURASE* \\ Osaka Branch, Okayama Laboratory, NISSHOKU Corporation, Sakai, Osaka 599-8570, Japan \\ * Graduate School of Life and Environmental Science, Osaka Prefecture University, \\ Sakai, Osaka 599-8531, Japan
}

(Received March 30, 2009)

\begin{abstract}
A dynamic model for simulating recombinant protein production in transgenic lettuce for optimum environmental control was developed. The model comprised three main parameters, which were leaf fresh weight, the number of cells, and amount of protein in each leaf. The differential equations of the model were integrated using the modeling software STELLA ${ }^{\mathrm{TM}}$. The model was calibrated based on the measured data of transgenic lettuce plants which were grown in a plant factory for 50 days from seeding. The plants contained an introduced Cauliflower mosaic virus-35S promoter fused onto the $\beta$-glucuronidase gene. Simulations were conducted to investigate the effect of plant growth control on the productivity of recombinant proteins which have various stabilities. The simulations indicated the importance of recombinant protein stability. If the parameters corresponding to the production and degradation of a recombinant protein can be identified, the simulation will be a strong tool for devising an environmental control strategy for highly efficient recombinant protein production systems.
\end{abstract}

Keywords : beta-glucuronidase, CaMV-35 promoter, edible vaccine, modeling

\section{INTRODUCTION}

Recombinant DNA technology in higher plants has opened up a new field in plant science (Yoshida and Shinmyo, 2000), and numerous recombinant protein production systems are utilized today. Transgenic crop plants have been considered as promising systems for bulk production of antibodies at relatively low cost (Smith, 1996; Daniell et al., 2001; Streatfield et al., 2001). Kusnadi et al. (1997) estimated that the cost of producing recombinant proteins in plants could be 10- to 50-fold lower than producing the same protein by Escherichia coli fermentation. Daniell et al. (2001) indicated that purification requirements could be eliminated if the antibody-containing plant tissue was used as a food (edible vaccine).

A plant factory as a closed system is suitable for producing recombinant proteins, because transgenic plants can be isolated perfectly from the outer environment. In addition, a plant factory provides precise environmental control (Morimoto et al., 1995; Murase, 2002; Shimizu et al., 2005), including some environmental conditions not existing in nature, to enhance the productivity of recombinant proteins.

Lettuce, one of the most popular leafy vegetables in the world, has already been used for

Corresponding author: Tsuyoshi Okayama, fax: +81-72-240-2126, e-mail : okayama@bics.envi.osakafu-u.ac.jp 
heterologous protein production (Kapusta et al., 1999; Sun et al., 2006; Webster et al., 2006; Kim et al., 2007; Li et al., 2007). Non-transgenic lettuce is cultivated at many plant factories which are operated commercially. Therefore, cultivation methods for lettuce which is used for ordinary food in a closed system have been established.

When a transgenic lettuce plant is used as a host plant, most of the recombinant protein will be stored in leaves. Stevens et al. (2000) investigated the relationship among leaf senescence, environmental conditions (temperature and light intensity) and the amount of antibody (IgG) expression tobacco. In their results, the top (young) leaves contained more or less twice the amount of antibodies than did the base (old) leaves. Their study indicates that proteolytic degradation triggered by leaf senescence activity can be an important factor affecting recombinant protein produced by transgenic plants.

These results indicate that the concentration of a recombinant protein in a leaf varies depending on leaf age and environmental factors. Therefore, a new methodology is required in order to evaluate the productivity of a recombinant protein in a lettuce plant. Okayama et al. (2008) developed a model for simulating the recombinant protein production in transgenic lettuce. The model focused on the time course of the leaf fresh weight and the concentration of the total soluble protein (TSP) in the leaf. In the model, TSP was used instead of a recombinant protein based on the assumption that TSP and a recombinant protein have a linear relationship. However, some recombinant proteins produced in transgenic lettuce plants have no significant relation with TSP (Sun et al., 2006; Okayama et al., 2009). Therefore, a recombinant protein should be used as a parameter instead of TSP. In addition, in the previous model, the time course of leaf fresh weight and TSP concentration were expressed statistically using logistic functions. Therefore, interactions between the factors were not described in the model.

The objectives of this study were to use a recombinant protein ( $\beta$-glucuronidase: GUS) instead of TSP, and to improve the previous model using dynamic simulation modeling to describe the interactions between factors. A simulation was conducted to investigate the effect of recombinant protein stabilities on the productivity of recombinant proteins.

\section{MATERIALS AND METHODS}

\section{Model description}

This model, which is an improved version of the model suggested by Okayama et al. (2008), predicts the time course of an amount of a recombinant protein which accumulates in a transgenic lettuce. The model comprises three main parameters, which are leaf fresh weight, the number of cells, and amount of protein in each leaf. The differential equations of the model were integrated using the modeling software STELLA ${ }^{\mathrm{TM}}$ (ver. 9.0.3, isee systems Inc., USA) a high level visualoriented programming and simulation language. Figure 1 shows the STELLA ${ }^{\mathrm{TM}}$ diagram of the model.

The total amount of the recombinant protein in a plant $T P(t)(\mu \mathrm{g})$ on day $t$ after seeding is expressed by the summation of amounts of the recombinant protein in all leaves:

$$
T P(t)=\sum_{i=1}^{L_{N}} P_{L}(t)_{i}
$$

where $P_{L}(t)_{i}(\mu \mathrm{g})$ is the amount of the recombinant protein in the $i$ th leaf and $L_{N}$ is the number of leaves.

$P_{L}(t)_{i}$ can be calculated from the balance between the recombinant protein production $P p_{i}(\mu \mathrm{g}$ $\left.\mathrm{d}^{-1}\right)$ and the recombinant protein degradation $P d_{i}\left(\mu \mathrm{g} \mathrm{d}^{-1}\right)$ :

$$
P_{L}(t)_{i}=P_{L}(t-d t)_{i}+\left(P p_{i}-P d_{i}\right) \cdot d t
$$




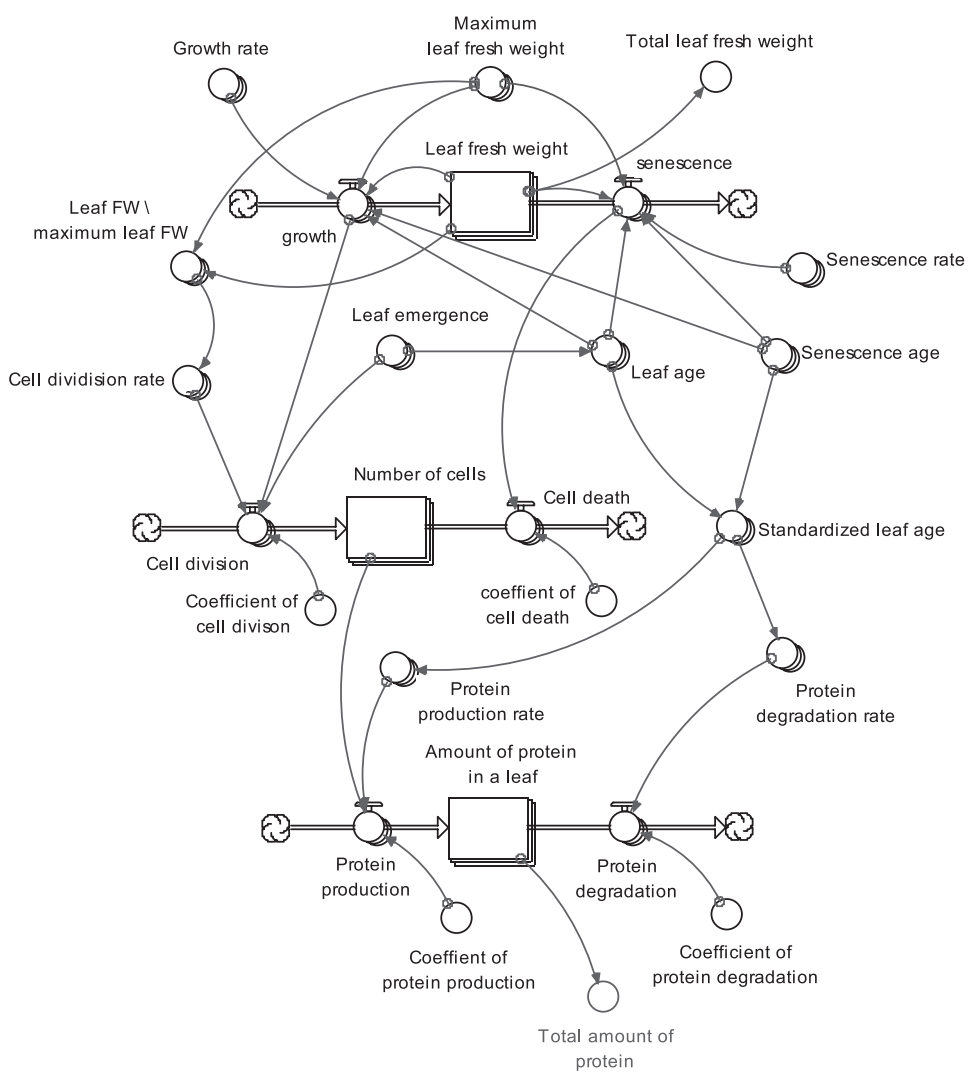

Fig. 1 The STELLA ${ }^{\mathrm{TM}}$ diagram of the model for recombinant protein production in a transgenic lettuce plant. Here, "protein" means "a recombinant protein".

$P p_{i}$ and $P d_{i}$ are given by:

$$
\begin{aligned}
P p_{i} & =c P p \cdot P p r_{i} \cdot N C(t)_{i} \\
P d_{i} & =c P d \cdot P d r_{i}
\end{aligned}
$$

where $c P p\left(\mu \mathrm{g} \mathrm{d}^{-1}\right.$ cell $\left.{ }^{-1}\right)$ and $c P d\left(\mu \mathrm{g} \mathrm{d}^{-1}\right)$ are the coefficient of the recombinant protein production and the coefficient of the recombinant protein degradation, respectively. $P p r_{i}$ (dimensionless) and $P d r_{i}$ (dimensionless) are the recombinant protein production rate and the recombinant protein degradation rate. $P p r_{i}$ and $P d r_{i}$ are described later. $N C(t)_{i}$ is the number of cells of the $i$ th leaf.

The number of cells and the leaf fresh weight do not have a linear relation, because the increase in the leaf fresh weight is achieved not only by cell division but also by the increase in the volume of cells resulting from the uptake of water into vacuoles (Mohr and Schopfer, 1995). Sunderland (1960) investigated the relationship between the leaf fresh weight and the number of cells in leaves of Helianthus annuus (sunflower) and found that cell division ceased when the leaf fresh weight reached around three-quarters of the maximum leaf fresh weight, and expansion continued after the cessation of cell division. In the present model, $N C(t)_{i}$ was calculated by:

$$
N C(t)_{i}=N C(t-d t)_{i}+\left(\operatorname{Cinc}_{i}-\operatorname{Cdec}_{i}\right) \cdot d t
$$

where $\operatorname{Cinc}_{i}\left(\right.$ cell d $\left.^{-1}\right)$ is an increase, and $\operatorname{Cdec}_{i}\left(\right.$ cell d $\left.^{-1}\right)$ is a decrease in the number of cells. Cinc $_{i}$ was arbitrarily adjusted to stop the increase of $N C(t)_{i}$ when the leaf fresh weight reached three- 


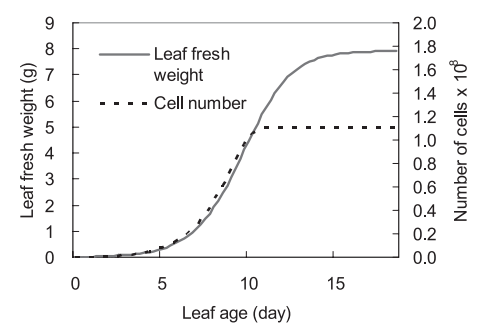

Fig. 2 An example of the relation between the number of cells and leaf fresh weight.

quarters of the maximum leaf fresh weight, and $C d e c_{i}$ was also arbitrarily adjusted to the decrease of the leaf fresh weight in the senescence phase.

Figure 2 shows an example of the time course of leaf fresh weight and the number of cells in the leaf. At the beginning, the leaf fresh weight and the number of cells increase with almost the same ratio. However, the cell division ceases before the leaf fresh weight reaches the maximum value.

Fresh weight of $i$ th leaf $L_{F W}(t)_{i}(\mathrm{~g})$ is given by:

$$
L_{F W}(t)_{i}=L_{F W}(t-d t)_{i}+\left(L g r_{i}-L s e_{i}\right) \cdot d t
$$

Where $L g r_{i}$ is an increase in fresh weight (growth) $\left(\mathrm{g} \mathrm{d}^{-1}\right)$ and $L s e_{i}$ is a decrease in fresh weight (senescence) $\left(\mathrm{g} \mathrm{d}^{-1}\right)$ of the $i$ th leaf. These parameters in growth phase and in senescence phase were different. The growth phase is defined a period when $L_{F W}(t)_{i}$ is increasing, and the senescence phase is defined a period when $L_{F W}(t)_{i}$ is decreasing. Therefore, senescence age $\operatorname{Sage}_{i}(\mathrm{~d})$ is defined the leaf age $\operatorname{Lage}_{i}(\mathrm{~d})$ when $L_{F W}(t)_{i}$ starts decreasing.

When Lage $_{i}$ is younger than Sage $_{i}$ (growth phase),

$$
\begin{aligned}
& \operatorname{Lgr}_{i}=\operatorname{rgr}_{i} \cdot\left(L_{F W} \max _{i}-L_{F W}(t)_{i}\right) \cdot L_{F W}(t)_{i} \\
& \operatorname{Lse}_{i}=0
\end{aligned}
$$

when $\operatorname{Lage}_{i}$ is older than $\operatorname{Sage}_{i}$ (senescence phase),

$$
\begin{aligned}
\operatorname{Lgr}_{i} & =0 \\
L s e_{i} & =r s e_{i} \cdot\left(L_{F W} \max _{i}-L_{F W}(t)_{i}\right) \cdot L_{F W}(t)_{i}
\end{aligned}
$$

Where $L_{F W} \max _{i}(\mathrm{~g})$ is the maximum leaf fresh weight of the $i$ th leaf, and $r g r_{i}\left(\mathrm{~g}^{-1} \mathrm{~d}^{-1}\right)$ is the growth rate, and $r s e_{i}\left(\mathrm{~g}^{-1} \mathrm{~d}^{-1}\right)$ is the senescence rate of the $i$ th leaf.

Recombinant protein production rate and degradation rate

When and how much a recombinant protein is produced and degraded in a leaf are important factors for the accumulation of a recombinant protein in a plant. In the present model, these parameters are defined through reasonable assumptions, because available information about these parameters is very limited. It is reasonable to assume that the younger (more vigorous) leaves produce more recombinant protein than the older leaves. Furthermore, the recombinant protein in the older leaves is degraded rapidly because of the senescence. In this model, these parameters were assumed to be functions of leaf age. The following sigmoid functions are used to describe the recombinant protein production rate $P p r_{i}\left(\mu \mathrm{g} \mathrm{d}^{-1}\right)$ and the recombinant protein degradation rate $P d r_{i}$ $\left(\mu \mathrm{g} \mathrm{d}^{-1}\right)$ : 


$$
\begin{aligned}
& P p r_{i}=1-\frac{1}{1+\exp \left(-c P p \cdot\left(\operatorname{Las}_{i}-P d t\right)\right)} \\
& P d r_{i}=\frac{1}{1+\exp \left(-c P d \cdot\left(\operatorname{Las}_{i}-D i t\right)\right)}
\end{aligned}
$$

Where $P d t$, Dit and $\operatorname{Las}_{i}$ are the time at which recombinant protein production degradation starts, the time at which recombinant protein degradation increases, and standardized leaf age, respectively. $\operatorname{Las}_{i}$ is described by:

$$
\operatorname{Las}_{i}=\frac{\operatorname{Lage}_{i}}{\operatorname{Llon}_{i}}
$$

In order to apply the same functions to all leaves, the standardized leaf age $\operatorname{Las}_{i}$ was used. $\operatorname{Las}_{i}$ is divided by its leaf longevity $\left(\right.$ Llon $\left._{i}\right)$. Llong $i$ was decided with the observation in the experiment. $P d t$ and Dit are the respective times when the protein production rate and the protein degradation rate become 0.5 (Fig. 3).

\section{Model calibration}

The experimental data used for calibrating the model was obtained with following procedures. Details of the data were reported in Okayama et al. (2009).

\section{Plant material and growth condition}

Leaf lettuce (Lactuca sativa L. cv. 'Greenwave') was used as the host plant. The binary vector was pBI121 (Clonetech Inc., USA) containing the neomycine phosphotrasferase II (NPTII) gene, conferring kanamycin resistance, and the GUS gene containing a functional intron within its coding region under the control of the CaMV-35S promoter. Primary transformants (T0 generation) were self-pollinated and their $\mathrm{T} 1$ progenies were self-pollinated to obtain $\mathrm{T} 2$ seeds in a closed growth chamber. The seeds were used in the experiment.

The transgenic lettuce plants were grown from the seeds in the plant factory at Osaka Prefecture University, Osaka, Japan. The photo/dark cycle was $14 / 10 \mathrm{~h} \mathrm{~d}^{-1}$. Light intensity was approximately $250 \mu \mathrm{mol} \mathrm{m}^{-2} \mathrm{~s}^{-1}$ PPFD (photosynthetic photon flux density) and was provided by fluorescent lamps. A half-strength nutrient solution (A-type Otsuka formula, Otsuka Chemical Co., Ltd., Japan) at $\mathrm{pH} 6.0$, electrical conductivity of $0.12 \mathrm{~S} \mathrm{~m}^{-1}$, was supplied to the plants using the deep flow technique. $\mathrm{CO}_{2}$ level was maintained at approximately $1,000 \mu \mathrm{mol} \mathrm{mol}^{-1}$. Air temperature and relative humidity were kept at $23 / 18^{\circ} \mathrm{C}$ and $50 / 80 \%$ (photo/dark period), respectively.

GUS expression measurement

Quantitative evaluations of GUS expression were carried out following Jefferson et al. (1987). Extracts were prepared from lettuce leaves using about $20 \mathrm{mg}$ fresh weight of tissue ground in a $250 \mu \mathrm{l}$ extraction buffer consisting of $50 \mathrm{mM}$ sodium phosphate at $\mathrm{pH} 7.0,10 \mathrm{mM}$ EDTA, $0.1 \%$ Triton X-100, 0.1\% sodium lauryl sarcosyl, and $10 \mathrm{mM}$ 2-mercaptoethanol. The homogenate was
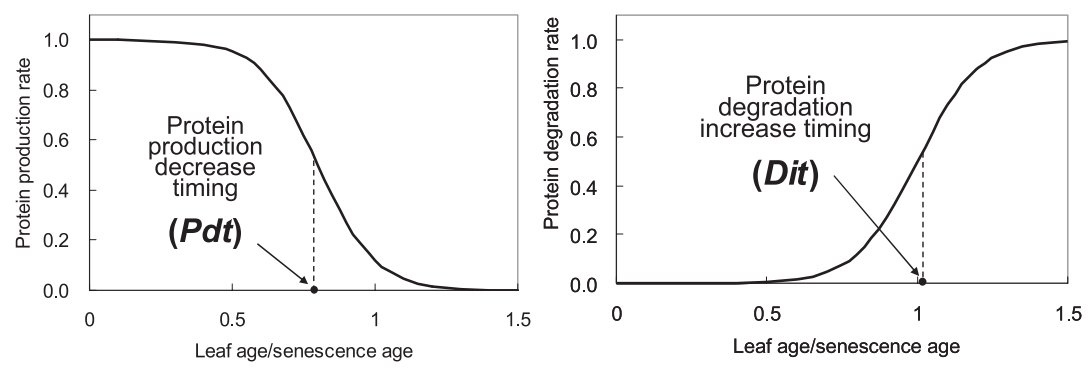

Fig. 3 Examples of time courses of protein production and degradation rate. 
centrifuged for $5 \mathrm{~min}$ at $12,000 \mathrm{rpm}$ at $4^{\circ} \mathrm{C}$. A soluble extract was used to determine GUS activity with $1 \mathrm{mM} 4$-methylumbelliferyl $-\beta$-D-glucuronide as a substrate. The reaction was incubated at $37^{\circ} \mathrm{C}$ for $60 \mathrm{~min}$, and $100 \mu \mathrm{l}$ aliquot was removed and $2 \mathrm{ml} 0.2 \mathrm{M} \mathrm{Na}_{2} \mathrm{CO}_{3}$ was added to stop the enzyme reaction. The reaction product 4-methylumbelliferone (MU) was detected with a fluorescence spectrophotometer (F-7000, Toshiba Co., Ltd., Japan) at $365 \mathrm{~nm}$ excitation/460 nm emission. This GUS activity (nmol min ${ }^{-1} \mathrm{gFW}^{-1}$, nmol $\mathrm{min}^{-1}$ leaf ${ }^{-1}$, or nmol min ${ }^{-1}$ plant $^{-1}$ ) was used for expressing the quantitative accumulation of the GUS protein.

Leaf fresh weight and GUS activity were measured at 25, 30, 40, and $50 \mathrm{~d}$ after seeding. Five individuals were measured at 25 and $30 \mathrm{~d}$ and three individuals were measured at 40 and $50 \mathrm{~d}$.

\section{Simulation of recombinant protein stability}

One of the factors that limit the accumulation of a recombinant protein is its stability (Stoger et al., 2002). Therefore, the timing of recombinant protein degradation increase (Dit), which represents stability, was varied from 0.4 (assuming the recombinant protein to be unstable) to 1.2 (stable) to investigate the effect of the recombinant protein stability on the accumulation of a recombinant protein in a lettuce plant. In order to simplify the explanations in the simulation, the unit of a recombinant protein was assumed to be ' $\mu \mathrm{g}$ ', instead of ' $\mathrm{nmol} \mathrm{min}^{-1}$ ' for GUS protein.

\section{RESULTS AND DISCUSSION}

\section{Calibration of the model}

The maximum leaf fresh weight of each leaf and the time course of the number of leaves were determined with measured values, and were expressed using a sigmoid function and a cubic curve, respectively (Fig. 4).

Figure 5 shows the time course of total leaf fresh weight (left) and the distribution of each leaf fresh weight at $50 \mathrm{~d}$ after seeding (right). Simulated and measured total leaf fresh weight showed
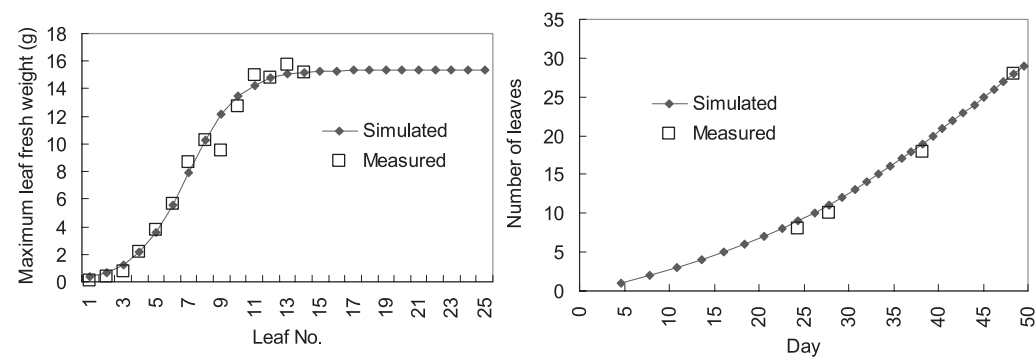

Fig. 4 Simulated and measured maximum leaf fresh weight of each leaf (left) and the time course of the number of leaves (right). The number of samples for measured values was 3 .
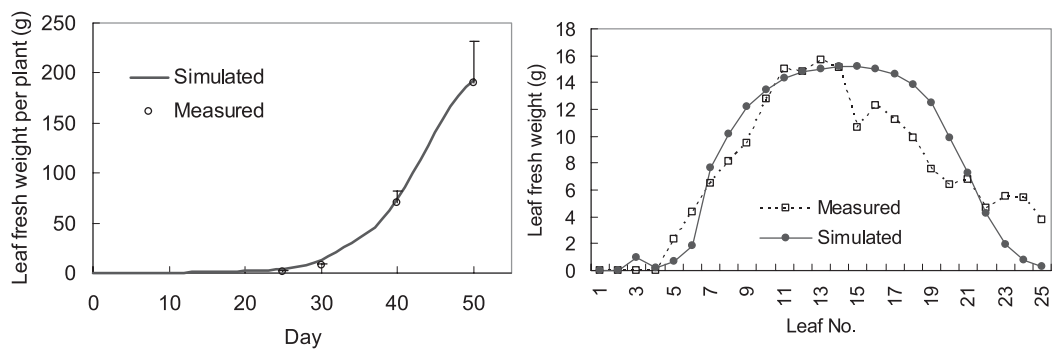

Fig. 5 The time course of total leaf fresh weight (left) and leaf fresh weight distribution at $50 \mathrm{~d}$ after sowing (right). 
good agreement. Simulated leaf fresh weights at $50 \mathrm{~d}$ after seeding were overestimated for leaves 15 to 19 , and underestimated for leaves 22 and above. The reason for these discrepancies was probably the complex effects of the competition for light, space, etc. In order to consider these effects in the model, two- or three-dimensional information will be necessary.

The curves of the protein production rate $(P d t=1.0)$ and degradation rate $(D i t=1.2)$ against the standardized leaf age were estimated based on the calibration data (Fig. 6). This result agrees with Benfey and Chua's finding (1990) that the CaMV-35S promoter conferred constitutive expression on heterologous genes and with Jefferson et al.'s finding (1987) that the GUS protein was very stably accumulated in plant tissue.

Figure 7 shows the distribution of GUS activity of each leaf at $50 \mathrm{~d}$ after seeding (left) and the time course of total GUS activity (right). There was good agreement between measured and simulated total GUS activity.

\section{Simulation of recombinant protein stability}

Figure 8 shows the simulated time course of the amount of recombinant protein in leaf No. 7 with different Dit (from 0.4 to 1.2). When Dit was 0.4 , no recombinant protein was accumulated because the amount of produced recombinant protein was equivalent to the amount of degraded re-

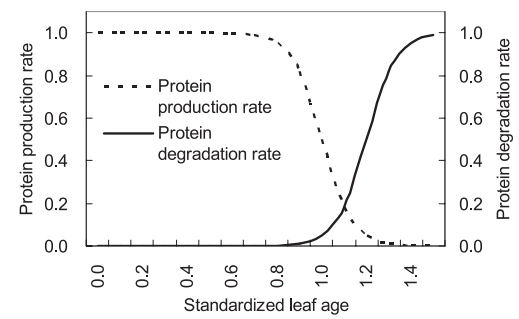

Fig. 6 Relationship between standardized age and protein production and degradation rates.
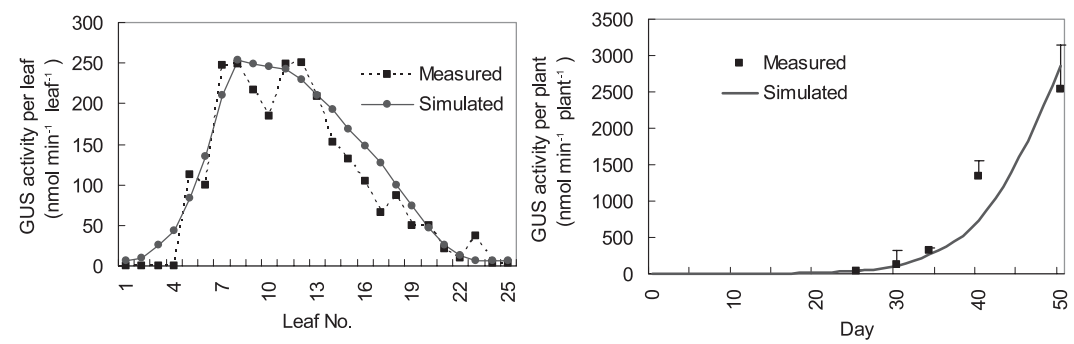

Fig. 7 Distribution of GUS activity per leaf at $50 \mathrm{~d}$ after seeding (left) and the time course of total GUS activity (right).

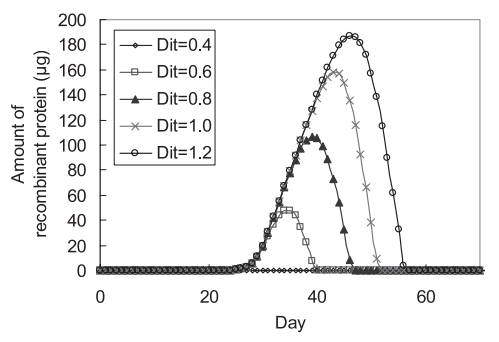

Fig. 8 The time course of the amount of recombinant protein in Leaf No. 7 with different Dit (from 0.4 to $1.2)$. 
combinant protein. When Dit was 0.6 , the maximum amount of the recombinant protein was 48.1 $\mu \mathrm{g}$, and the recombinant protein remained in the leaf for 18 days. In contrast, when Dit was 1.2, the maximum amount of the recombinant protein was $186.8 \mu \mathrm{g}$, and the recombinant protein remained in the leaf for 35 days.

Figure 9 shows the total amount of the recombinant protein at $50 \mathrm{~d}$ after seeding for various Dit. When Dit was 1.2, the amount of total protein was $2,789 \mu \mathrm{g}$. On the other hand, when the Dit was 0.4 , the amount of total protein was only $253 \mu \mathrm{g}$. Figure 10 shows the distribution of the amount of the protein in each leaf at $50 \mathrm{~d}$ after seeding when Dit was 0.4. Although leaves 7 to 12 remained with large fresh weight, they contained no recombinant protein because of the protein degradation. These results illustrate the inefficiency of unstable recombinant protein.

The assumptions of recombinant protein production and degradation which were used in the simulations were too simple. Therefore, influences of environmental conditions on a recombinant protein must be investigated in further studies.

The model developed in this paper suggested that a longer cultivation period (more than 50 days from seeding) would be more efficient for accumulating a recombinant protein than the period (40 to 50 days from seeding) used in conventional plant factories. However, if the cultivation period is excessively long, lettuce plants will bolt and their height will exceed two meters with fewer leaves. Bolting is, therefore, unfavorable for the accumulation of a recombinant protein in leaves and cultivation in a plant factory. Therefore, the optimum cultivation cycle should be more than $50 \mathrm{~d}$ from seeding, but before bolting. It should be noted that tipburn may be a serious problem for longer cultivation periods. To prevent tipburn, attention should be paid to the air circulation system (Goto and Takakura, 1992). If a longer cultivation period is employed, the lettuce will be much bigger than the conventional size. Therefore, the optimum plant density should be reconsidered for an efficient production system (Seginer and Ioslovich, 1999).

If the findings described above can be integrated into the simulation model, the simulation will become a strong tool for devising an environmental control strategy for a highly efficient recombinant protein production systems.

This research was financially supported by the Japanese Ministry of Economy, Trade and Industry, and conducted as part of the "Development of Fundamental Technologies for the Production of High-value Materials using Transgenic Plants (2006-2010)" project. We are especially grateful to Dr. Asao (Nara Prefectural Agriculture Experimental Station), and Dr. Sawada and Dr. Matsui (Idemitsu Kosan Co., Ltd.) for providing the primary transformants, and to Mr. Mizue for his useful advice.

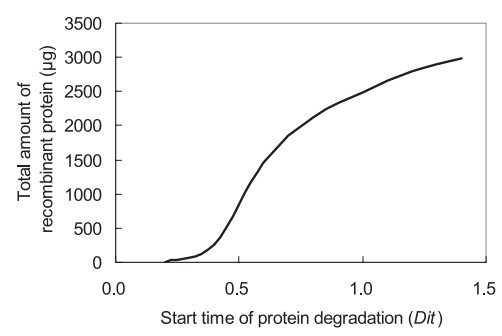

Fig. 9 Total amount of the recombinant protein at $50 \mathrm{~d}$ after seeding for various starting times of protein degradation.

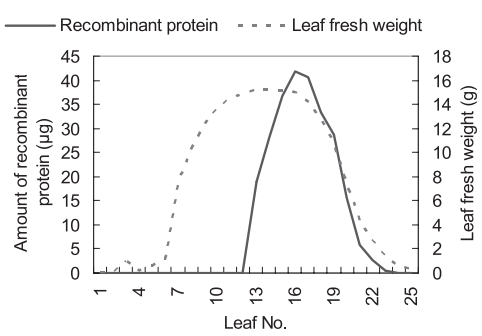

Fig. 10 The distribution of the amount of recombinant protein in each leaf and leaf fresh weight at $50 \mathrm{~d}$ after seeding $(P d i=0.4$ : the recombinant protein is very unstable). 


\section{REFERENCES}

Benfey, P. N., Chua, N.-H. 1990. The cauliflower mosaic virus 35s promoter: Combinatorial regulation of transcription in plants. Science 250: 959-966.

Daniell, H., Streatfield, S. J., Wycoff, K. 2001. Medical molecular farming: Production of antibodies, biopharmaceuticals and edible vaccines in plants. Trends in Plant Science 6: 219-226.

Goto, E., Takakura, T. 1992. Prevention of lettuce tipburn by supplying air to inner leaves. Trans. ASAE 35: $641-645$.

Jefferson, R. A., Kavanagh, T. A., Bevan, M. W. 1987. Gus fusions: B-glucuronidase as a sensitive and versatile gene fusion marker in higher plants. The EMBO Journal 6: 3901-3907.

Kapusta, J., Modelska, A., Figlerowicz, M., Pniewski, T., Letellier, M., Lisowa, O., Yusibov, V., Koprowski, H., Plucienniczak, A., Legocki, A. B. 1999. A plant-derived edible vaccine against hepatitis b virus. FASEB J. 13: 1796-1799.

Kim, T.-G., Kim, M.-Y., Kim, B.-G., Kang, T.-J., Kim, Y.-S., Jang, Y.-S., Arntzen, C. J., Yang, M.-S. 2007. Synthesis and assembly of escherichia coli heat-labile enterotoxin b subunit in transgenic lettuce (Lactuca sativa). Protein Expression and Purification 51: 22-27.

Kusnadi, A. R., Nikolov, Z. L., Howard, J. A. 1997. Production of recombinant proteins in transgenic plants: Practical considerations. Biotechnol. Bioeng. 56: 473-484.

Li, J., Chen, M., Liu, X.-W., Zhang, H.-C., Shen, F. F., Wang, G. P. 2007. Transient expression of an active human interferon-beta in lettuce. Sci. Hortic. 112: 258-265.

Mohr, H., Schopfer, P. 1995. Plant physiology, 99. Springer-Verlag Berlin Heidelberg, New York, p 99.

Morimoto, T., Torii, T., Hashimoto, Y. 1995. Optimal control of physiological processes of plants in a green plant factory. Control Eng. Practice 3: 505-511.

Murase, H. 2002. Precision technologies for protected agriculture. ASAE Paper \#023034.

Okayama, T., Okamura, K., Murase, H. 2008. A simulation model for heterologous protein production in transgenic lettuce. Environ. Control Biol. 46: 195-202.

Okayama, T., Okamura, K., Murase, H. 2009. Time course of the expression of the camv35s-gus gene in transgenic lettuce plants in a plant factory. Engineering in Agriculture, Environment and Food 2: 83-88.

Seginer, I., Ioslovich, I. 1999. Optimal spacing and cultivation intensity for an industrialized crop production system. Agric. Syst. 62: 143-157.

Shimizu, H., Ma, Z., Tazawa, S., Douzono, M., Runkle, E., Heins, R. 2005. The application of blue light as a growth regulator. An ASAE Meeting Presentation 054152.

Smith, M. D. 1996. Antibody production in plants. Biotechnol. Adv. 14: 267-281.

Stevens, L. H., Stoopen, G. M., Elbers, I. J. W., Molthoff, J. W., Bakker, H. A. C., Lommen, A., Bosch, D., Jordi, W. J. 2000. Effect of climate conditions and plant developmental stage on the stability of antibodies expressed in transgenic tabacco. Plant Physiol. 124: 173-182.

Stoger, E., Sack, M., Perrin, Y., Vaquero, C., Torres, E., Twyman, R. M., Christou, P., Fischer, R. 2002. Practical considerations for pharmaceutical antibody production in different crop systems. Molecular Breeding 9: 149-158.

Streatfield, S. J., Jilka, J. M., Hood, E. E., Turner, D. D., Bailey, M. R., Mayor, J. M., Woodard, S. L., Beifuss, K. K., Horn, M. E., Delaney, D. E., Tizard, I. R., Howard, J. A. 2001. Plant-based vaccines: Unique advantages. Vaccine 19: 2742-2748.

Sun, H.-J., Cui, M.-1., Ma, B., Ezura, H. 2006. Functional expression of the taste-modifying protein, miraculin, in transgenic lettuce. FEBS Letters 580: 620-626.

Sunderland, N. 1960. Cell division and expansion in the growth of the leaf. J. Exp. Bot. 11: 68-80.

Webster, D. E., Smith, S. D., Pickering, R. J., Strugnell, R. A., Dry, I. B., Wesselingh, S. L. 2006. Measles virus hemagglutinin protein expressed in transgenic lettuce induces neutralising antibodies in mice following mucosal vaccination. Vaccine 24: 3538-3544.

Yoshida, K., Shinmyo, A. 2000. Transgene expression systems in plant, a natural bioreactor. Journal of Bioscience and Bioengineering 90: 353-362. 